\title{
BREAST MILK BANK-SAVES GENERATION
}

*Mrs. S. Rajeswari\& **Prof. P. Sumathy

\begin{abstract}
:
Breastfeeding is the best method of infant feeding because human milk continues to be the only milk which is tailor-made and uniquely suited to the human infant. All mothers should be encouraged to breast-feed their infants. When a mother, for some reason, is unable to feed her infant directly, her breast milk should be expressed and fed to the infant. If mother's own milk is unavailable or insufficient, the next best option is to use pasteurized donor human milk (PDHM). India faces its own unique challenges, having the highest number of low birth weight babies, and significant mortality and morbidity in very low birth weight (VLBW) population. Human Milk Banking Association should be constituted, and human milk banks should be established across the country. National coordination mechanism should be developed with a secretariat and technical support to follow-up on action in States. Budgetary provisions should be made available for theactivities.
\end{abstract}

Key words: Pasteurized donor Human Milk, Very Low Birth Weight, Human Milk Banking

\section{Introduction}

Breast milk is produced by the breast of a human female for her infant offspring. Milk is the primary source of nutrition for newborn before they eat solid food. The World Health Organization recommends exclusive breastfeeding for the first six months of life, with solids gradually being introduced around this age when signs of readiness are shown. Supplemented breastfeeding is recommended until at leastage two and then for as long as the mother and child wish. ${ }^{[1][2]}$

\section{Proteins}

Human milk contains two types of proteins: whey andcasein.

Approximately $60 \%$ is whey, while $40 \%$ is casein. This balance of the proteins allows for quick and easy digestion. If artificial milk, also called formula, has a greater percentage of casein, it will be more difficult for the baby to digest. human milk is whey protein. These proteins have great infection-protection properties.

Listed below are specific proteins that are found in breast milk and their benefits:

- Lactoferrininhibits the growth of irondependent bacteria in the gastrointestinal tract. This inhibits certain organisms, such as coliforms and yeast, that requireiron.

- Secretory IgA also works to protectthe infant from viruses and bacteria, specifically those that the baby, mom, and family are exposed to. It also helps to protect against E. coli and possibly allergies. Other immunoglobulins, including IgG and IgM, in breast milk also help protect against bacterial and viral infections. Eating fish can help increase the amount of these proteins in breast milk. 
- Lysozyme is an enzyme that protects the infant against E. coli and salmonella. It also promotes the growth of healthy intestinal flora and has anti-inflammatory functions.

- Bifidus factor supports the growth of lactobacillus. Lactobacillus is abeneficial bacterium

\section{thatprotects Benefits of Breast Feeding}

the baby Under the influence of the hormones against

harmful bacteria by creating an acidic environment where it cannot survive.

Fats

Human milk alsocontains fatsthat are essentialfor prolactin and oxytocin, women produce milk after childbirth to feed the baby. The initial milk produced is referred to as colostrum, which is high in the immunoglobulin IgA, which coatsthe gastrointestinal tract. This helps to protect the newborn until its own immune system is functioning properly. It also creates a mild laxative effect, expelling meconium and helping to prevent the build- up of bilirubin (a contributory factor in jaundice). Breast milk has the perfect combination of proteins, fats, vitamins, andcarbohydrates nutrition, includingvitaminsFatinfant'shealth. Water-soluble vitaminssuchasvitamin C,riboflavin, niacin, andpanthothenic acid are also essential. Because of the need for thesevitamins, many healthcare providers and Lactation consultantswill have nursing mothers continue on prenatal vitamins.

\section{Carbohydrates Lactose isthe primarycarbohy drate found in human milk.}

mother's vitamin intake. This iswhy it isessential that she getsadequate 


It accounts
forapproximately $40 \%$ of
the total calories provided
by breast milk. Lactose
helps to decrease
theamount of unhealthy
bacteria in the stomach,
which improves the
absorption of calcium,
phosphorus, and
magnesium. It
helpstofightdisease and
promotes thegrowth of
healthy bacteria in
thestomach.

\section{Expressed breastmilk}

For some reason, when the mother is unable to feed her infant directly, her breast milk should be expressed and fed to the infant. It is still safe to use, and most babies will drink it. Scalding it will prevent rancid 
taste at the expense of antibodies ${ }^{4}$. It should be stored with airtight seals. Some plastic bags are designed for storage periods of less than 72 hours. Others can be used for up to 12 months if frozen.

This table describes safe storage time limits.

\begin{tabular}{|l|l|l|l|}
\hline Place of storage & \multicolumn{2}{l|}{ Temperature } & $\begin{array}{l}\text { Maximum storage } \\
\text { time }\end{array}$ \\
\hline In a room & $25^{\circ} \mathrm{C}$ & $77^{\circ} \mathrm{F}$ & Six to eight hours \\
\hline Insulated thermal bag with ice packs & & & Up to 24 hours \\
\hline In a refrigerator & $4{ }^{\circ} \mathrm{C}$ & $39^{\circ} \mathrm{F}$ & Up to five days \\
\hline Freezer compartment inside a refrigerator & $-15^{\circ} \mathrm{C}$ & $5{ }^{\circ} \mathrm{F}$ & Two weeks \\
\hline $\begin{array}{l}\text { A combined refrigerator and freezer with separate } \\
\text { doors }\end{array}$ & $-18^{\circ} \mathrm{C}$ & $0{ }^{\circ} \mathrm{F}$ & Three to six months \\
\hline Chest or upright manual defrost deep freezer & $-20{ }^{\circ} \mathrm{C}$ & $-4{ }^{\circ} \mathrm{F}$ & Six to twelve months \\
\hline
\end{tabular}

\section{Breast milk Bank}

In some mothers own milk is unavailable or insufficient, the next best option is to use pasteurized donor human milk (PDHM). India faces its own unique challenges, having the highest number of low birth weight babies, and significant mortality and morbidity in very low birth weight (VLBW) population. In our country, the burden of low birth weight babies in various hospitals is about $20 \%$ with significant mortality and morbidities ${ }^{5}$. Feeding these babies with breast milkcan significantly reduce the risk of infections. Hence the Government, health experts and the civil society must join hands to propagate the concept of human milk banking for the sake of thousands of low birth weight and preterm babies. The first milk bank in Asia under the name of Sneha, founded by Dr. Armeda Fernandez, was started in Dharavi, Mumbai on November 27, 1989. Currently, the number of human milk banks (HMB) has grown to nearly 14 all over India but the growth of human milk banks has been very slow as compared to the growth of neonatal intensive careunits. 
In Tamil Nadu Breast Milk Banks were inaugurated in seven state-run hospitals in Tiruchirappalli, Madurai, Coimbatore, Theni, Salem and Thanjavur, besides the over 160-year old Government Institute of Obstetrics and Gynaecology and Hospital at Egmore. Each bank has been provided with equipment worth Rs. 10 lakhs to preserve the milk donated by mothers. Such milk can be stored for three months and will be given to babies who cannot get milk from theirmothers.

\section{LOCATION OF HUMAN MILK BANKS}

Human milk banks are primarily focused to provide donor milk to high-risk newborns admitted in the Neonatal unit. Therefore, a location in close proximity or even inside the boundaries of neonatal unit is desirable. This also helps in administrative supervision by medical staff. Presence of human milk banks in the neonatal units is associated with elevated rates of exclusive breastfeeding rates in VLBW babies

\section{The Recipients}

PDHM (Pasteurized Donor Human Milk) can be prescribed on priority for preterm babies and sick babies, babies of mothers with postpartum illnesses, and babies whose mothers have lactation failure, till their milk output improves. Absent or insufficient lactation: Mothers with multiple births, who cannot secrete adequate breast milk for their neonates initially.

If PDHM supplies are sufficient donor milk may be supplied
- For babies of non-lactating mothers, who adopt Neonates and if induced lactation is notpossible.

- Abandoned neonates and sickneonates.

- Temporary interruption ofbreastfeeding.

- Infant at health risk from breast milk of the biologicalMother.

- Babies whose mother died in the immediate postpartumperiod

\section{EQUIPMENTS}

- Pasteurizer/Shaker-water bath :Device to carry out heat treatment of donor milk at the recommended temperature of $62.5^{\circ} \mathrm{C}$ for a period of 30 minutes (Pretoria Holder pasteurization method) prior to itsuse

- Deep freezer: A deep freezer to store the milk at $-200^{\circ} \mathrm{C}$ is essential in the milk bank.

- Refrigerators

- Hot airoven/Autoclave

- Breast milkpumps

- Containers Generator/Uninterrupted power supply

- Milk analyzer: It is desirable to have macronutrient analysis of breastmilk

\section{General Guidelines for Staff of the Human MilkBank}

Standard operating procedures (SOP) of the bank (which should be displayed at proper places) should be adhered to.

- Hygienic practices like proper hand wash, donning gowns, mask, gloves, trimming nails, locking long hairs should be maintained.

- Gloves should be worn and changed between handling raw and heat-treatedmilk. 
- Staff should undergo regular health checks and be immunized against HepatitisB.

- There should be a program for ongoing training of thestaff

\section{Criteria for breast milk donors Who can donate?}

A lactating woman who:

- is in good health, good health-related behaviour, and not regularly on medications or herbal supplements (with the exception of prenatal vitamins, human insulin, thyroid replacement hormones, nasal sprays, asthma inhalers, topical treatments, eye drops, progestin-only or low dose estrogen birth controlproducts);

- is willing to undergo blood testing for screening of infections;and

- has enough milk after feeding her baby satisfactorily and baby is thriving nicely.

Who cannotdonate?

A donor is disqualified who:

- uses illegal drugs, tobacco products or nicotine replacement therapy;or

- regularly takes more than two ounces of alcohol or its equivalent or threecaffeinated drinks per day; or

- Has a positive blood test result forHIV,HCV, Hepatitis b or c or syphilis;or

- Is herself or has a sexual partner suffering from $\mathrm{HBsAg}, \mathrm{HIV}, \mathrm{HCV}$ and Venereal diseases or either one has high risk behaviour for contracting them in last 12 months; or

- Has received organ or tissue transplant, any blood transfusion/blood productwithin the prior 12 months.

- Is taking radioactive or other drugs or has chemical environmental exposure or over the counter prescriptions or mega dosesof vitamins, which are known to be toxic to the neonate and excreted in breast milk; or has mastitis or fungal infection of the nipple or areola, active herpes simplex or varicella zoster infections in the mammary or thoracic region ${ }^{6}$.

\section{Nurses Role in collection of breast milk}

- Propercounselling

- Checking suitability fordonation

- Getting written informedconsent

- Historytaking

- Physical examination and sampling for laboratorytests

- The donor is sent to designated breast milk collection area in the milk bank or in the milk collectioncentre.

- Breast milk is collected by trained staff with hygienicprecautions

- Method of breast milk expression is chosen by thedonor.

- Home collection of breast milk is better avoided at present in our country due of the risk ofcontamination.

- Washing the breast with water before expression is as good as washing with disinfectant ${ }^{7}$.

\section{Processing}

All batches of collected raw breastmilk should be refrigerated immediately till the serological report comes negative. Fresh raw milk should not be added to the frozen milk since this can result in defreezing with hydrolysis of triglycerides [8]. While mixing fresh raw breastmilk to frozen raw breastmilk previously collected from same donor, it should be chilled before adding to frozen milk [9]. For sick or preterm babies, 
it is advisable to use a new container for each pumping. Before pasteurization, pooling and mixing may be carried out from multiple donors to ease the process of processing and storage. Pasteurization is carried out by Holder's method. Microbiological screening of donor milk is done before (if there is no cost constraint), and as soon as possible after pasteurization. Pre-pasteurization microbiology can result in wastage of milk to the tune of about $30 \%$ in some cases ${ }^{10}$. Even after pasteurization, the endotoxins of organisms are still present in the milk in some cases but they have not been found to have any clinical effect on the baby. A bacterial count of $105 \mathrm{CFU} / \mathrm{ml}$ or more in raw breastmilk can be considered as an indicator of the poor quality of milk. Based on this and on the theoretical concern that heavily contaminated milk with specific bacteria (e.g. S. aureus, E.coli) may contain enterotoxins and thermostable enzymes even after pasteurization, expert panel selected $105 \mathrm{CFU} / \mathrm{ml}$ for total bacterial count, 104 $\mathrm{CFU} / \mathrm{ml}$ for Enterobacteriaceae and $S$. aureus as threshold values, which are in consonance with milk banks operating in other parts of the world ${ }^{11 \& 12}$. No growth is acceptable in post-pasteurization microbiology cultures. Whole batch of culture positive container of pasteurized milk should bediscarded.

\section{Storage}

Pasteurized milk awaiting culture report should be kept in dedicated freezer/freezer area taking precaution not to disburse it till the culture is negative. Storage should be done in the same container that is used for pasteurization .Itis advisable not to transfer processed milk in other containers as it has risk of contamination. Culture negative processed milk should be kept at $-20^{\circ} \mathrm{C}$ in tightly sealed container with clear mention of expiry date and other relevant data on the label. It can be preserved for 3 to 6 months. Random cultures of preserved milk before disbursal can aid qualityassurance.

\section{Disbursal}

PDHM should be disbursed at physician's requisition from NICU physician after informed consent from the parents of the recepient. Preterm baby should preferably get PDHM from preterm donors Frozen PDHM should be thawed by either defrosting the milk rapidly in a water bath at a temperature not exceeding $37^{\circ} \mathrm{C}$, or under running lukewarm water taking care that the cap of the container does not come in contact with the water as it is likely to get contaminated $^{13}$. It should never be thawed in a microwave as this results in reduction in the $\operatorname{IgA}$ content of the milk and there is a risk of burns if the milk is used toosoon ${ }^{14}$.

\section{Labelling and record keeping}

Human milk bank should have an operational objective of ensuring full traceability from individual donation to recipient, and maintaining a record of all storage and processing conditions. Written standard operating procedures should be followed Proper labeling at all levels is mandatory; from sterile container for collection of donation, pooling vessel and pasteurization container to storage containers. Labels should be water resistant 
and names and identifying details of donors, dates of pasteurization, batch numbers and expiry date should be clearly readable. Record keeping at all levels should be meticulous for Donor Record File containing consent form, donor's and her child's data, screening reports, pasteurization batch files, and for PDHM Disbursal Record File containing relevant data, including recipient consent form. Though rarely required, complications can be prevented with appropriate labelling and recordkeeping.

Contact: Human Milk Bank

- M.G. Chadwaborivali medical brotherhood hall, Doctor's houseTPS- $111,51^{\text {st }}$ road, Borivali (W), Mumbai- 400042. Ph.no. 91022-28984887/28998942

- GH Egmore,Chennai

\section{CONCLUSION}

It is clear that artificial formula will never provide the broad range of benefits of human milk. Given the high rate of preterm births in the country and level of malnutrition that ensues in the postnatal growth in such babies after birth, there is an urgent need to establish milk banks across the country, especially in the large neonatal units of all hospitals. This document aims at providing expert opinion regarding thefeasibility and operational guidelines for establishing milk banks in thecountry.

\section{REFERENCE}

1. WHO Exclusive breastfeeding". Who.int. 2011-01-15. Retrieved2011-10-26.
Mental health, attachment andbreastfeeding: implications for adoptedchildren and their mothers", International Breastfeeding Journal,2006

3. Understanding the relationships between breastfeeding, malocclusion, ADHD, sleepdisordered breathing and traumatic dental injuries.Medical Hypotheses 80 (3):315320. doi:10.1016/j.mehy.2012.12.017. PMI D23306004

4. Bharati P, Pal M, Bandyopadhyay M, Bhakta A,Chakraborty S, BharatiP. Prevalence and causes of low birth weight in India. Malayasian J Nutr. 2011; 17:301-13.

5. Das BK, Mishra RN, Mishra OP, Bhargava V, Prakash A. Comparative outcome of low birth weight babies. Indian Pediatrics. 1993; 30:15-21

6. Breast Pumps. US FDA, Heal. Cent. Devices Radiol. Center for Devices and Radiological Health; 2013 Available from: http://www.fda.gov/MedicalDevices/Productsa nd Medical Procedures/Home Health and Consumer/Consumer Products /BreastPumps/ucm 061950. htm. Accessed November 14, 2013.

7. Pickler RH, Munro C, Shotwell J. Contamination in expressed breast milk following breast cleansing. J Hum Lact. 1997; 13:127-30.

8. Morera PS, CastelloteBargallo AI, Lopez Sabater MC. Evaluation by highperformance liquid chromatography of the hydrolysis of human milk triglycerides during storage at low temperatures. J Chromatogr A.1998;823:467-74.

9. CDC. Proper Handling and Storage of Human Milk. Recommendations. Breastfeeding. Available from: http:// www.cdc.gov/breastfeeding/recommendatio 